\title{
Fundamental Factors Controlling Electrical Resistivity in Vitreous Ternary Lead Silicates
}

\author{
Simon W. Strauss, ${ }^{1}$ Dwight G. Moore, William N. Harrison, and Lloyd E. Richards
}

\begin{abstract}
The resistivities of selected vitreous ternary lead silicates containing ions of groups I, II, III, IV, and also the ions chromium, manganese, iron, cobalt, and nickel were measured in the range $200^{\circ}$ to $500^{\circ} \mathrm{C}$ and at an applied direct-current field of 525 volts per centimeter. In addition, the resistivities of vitreous silica and of quartz, with optic axis parallel and perpendicular to the applied field, were measured over the same temperature range. The resulting data are given as log resistivity-composition isotherms for the alkalies and alkaline earths and as $\log$ resistivity-temperature curves for the other ions. Correlations between resistivity and bonding energy and between frequency factor and heat of activation are presented. The resistivities of the alkali lead silicates were interpreted from the standpoint of the activation energy principle.
\end{abstract}

\section{Introduction}

Studies of the high-temperature electrical resistivities of ceramic coating materials have become important from the standpoint of both theor $y$ and technology. The current investigation was in outgrowth of a project begun in 1951. At that time a request had been received from Army Ordnance to develop a high temperature, electrically insulating ceramic coating suitable for the replacement of the more strategic natural sheet mica in special electronic components which must operate at elevated temperatures. A literature survey revealed that conduction in vitreous silicates was believed to be caused mostly by the migration of alkali ions. Using this information as well as some empirical considerations, a number of alkali-free, high-resistivity ceramic coatings were developed. A paper discussing some of the results was published [1] ${ }^{2}$ and the data showed that ceramic coatings merit serious consideration in the field of high-temperature electrical insulation.

Although the ceramic coatings that were developed and tested proved suitable for a specific application, it was thought that a thorough study of fundamental factors controlling electrical resistivity in simple glass systems should be undertaken, to provide knowledge that could be applied not only in the design of ceramic coatings for use as high-temperature insulation, but also in the elucidation of the conduction mechanism. With these objectives in mind, a fundamental study was begun in 1952 under the sponsorship of the Office of Ordnance Research. This report covers the first phase of the study.

\section{Review of Conduction Theory in Glasses}

Investigations of the electrical properties of vitreous silicates were made as early as $1854[2,3]$. Seddon, Tippet, and Turner [4] have summarized the status

\footnotetext{
1 Present address, Naval Research Laboratory,'Washington, D. C.

2 Figures in brackets indicate the literature references at end of this paper.
}

in this field of study up to 1932 . More recent ideas regarding the conduction mechanism have been presented in articles by Morey [5], Murphy and Morgan [6], Stevels [7], Stanworth [8], and Eitel [9].

It is generally agreed by these investigators that conduction in glasses is ionic. It has been established that the electrical conductivity of a soda-limesilica glass, at room temperature and up to the strain point,${ }^{3}$ is essentially the result of transport of sodium ions, which are believed to migrate through the interstitial positions in the silicate network. In this temperature region the mobility of the calcium ion is considered to be negligible. The thermal energy is thought to be sufficient to detach a sodium ion fromitsinterstitial position and cause it to move to a neighboring position [10]. As long as no external field is applied, the probability of such migration is equal in all directions. However, in the presence of an imposed field the sodium ions will show a tendency to move with the direction of the field, thus causing an electric current. The sodium ion has either a lower charge or a smaller radius than the other network modifiers ${ }^{4}$ in a glass, with the exception of lithium; for this reason its movement through the lattice may be less restricted. Nevertheless, at sufficiently high temperatures the other network modifiers are said to contribute to the conductivity [7]. Relatively few systematic studies have heretofore been made on the conduction of simple glasses at temperatures exceeding $200^{\circ}$ C. Moore and DeSilva [11] studied the electrical properties of ternary and quaternary alkali lime glasses at temperatures up to $320^{\circ} \mathrm{C}$, and Gehlhoff and Thomas [12] measured electrical conduction of ternary soda silicates at temperatures up to $400^{\circ} \mathrm{C}$. The purpose of the present investigation was to provide information which might contribute to a better understanding of the conduction process in silicate structures.

3 I.illie, J. Am. Ceram. Soc. [3] 37, 117 (1954), recommended the strain point to be defined as that temperature at which the data from the annealing point test, when plotted logarithmically against temperature, extrapolate to a viscosity of $10^{14.50}$ poises.

${ }_{4}$ Network modifier ions usually occupy the interstitial positions in the glassy structure. 


\section{Selection of Compositions}

One of the objectives of the current investigation was to study the composition dependency of electrical resistivity of ceramic coating materials. It appeared that a logical approach was to select a simple silicate system for initial experimentation, and then to increase the complexity of the system by the gradually increasing partial replacement of one component ion at a time by other ions. In selecting a base composition, the system chosen should have a high solubility for various oxides and should yield workable glasses. Careful consideration of these and other problems involved, resulted in the selection of $\mathrm{PbO}: \mathrm{SiO}_{2}$ as the base composition. In a given composicion series, increasing amounts of lead oxide were replaced by one of the other oxides.

The structure of a glass may be modified considerably if the composition is changed over a wide range even if the same constituents are used throughout. To avoid such structural changes, the specimens were composed according to the formula $x \mathrm{MeO}:(1-x) \mathrm{PbO}: \mathrm{SiO}_{2}$. The value of $x$ ranged from 0 to 0.4 for the alkali and alkaline earth ions and for iron, cobalt, and nickel and was fixed at 0.4 for the other ions. The 0.4 mole replacement was selected because this was the maximum concentration for glass formation for some of the oxides, and volatilization losses could be kept to reasonable values. Equivalent replacement was used so as to keep a constant ratio of $\mathrm{Si} / \mathrm{O}$ and thus avoid any structural changes which might be caused by changes in the $\mathrm{Si} / \mathrm{O}$ ratio.

Resistivity measurements were made on quartz and silica glass and also on complex lead silicates in which part of the lead oxide was replaced by oxides of lithium, sodium, potassium, rubidium, cesium, beryllium, magnesium, calcium, strontium, barium, zinc, cadmium, boron, aluminum, lanthanum, titanium, germanium, zirconium, cerium, thorium, chromium, manganese, iron, cobalt, and nickel. The compositions of these glasses are given in table 1 .

\section{Materials and Preparation of Specimens}

All glasses were prepared from reagent grade chemicals (oxides, nitrates, carbonates, or oxalates); the source of silica was quartz crystals pulverized to pass a US Standard No. 40 sieve. Each raw batch was mixed intimately and ground in a mortar until all of the powdered material passed through a No. 40 sieve. The batches were melted in platinum crucibles placed in an electric furnace. Each melt was periodically stirred with a platinum rod to aid in the elimination of occluded gases and to produce a homogeneous glass. Test specimens were cast in a steel mold in the shape of a disk, $1 \frac{1}{2}$ in. in diameter by about $1 / 4$ in. thick. The disk, after casting, was transferred to a preheated ceramic mold and was then placed in an annealing: furnace where it was allowed to cool overnight. After cooling, the disk was ground flat on a grinding lap using SiC No. 150 and No. 320 as abrasives, and the thicknesses measured to the nearest 0.0001 in.
TABLE 1. Batch compositions of ternary lead silicates containing elements of groups $I, I I, I I I$, and $I V$, and chromium, manganese, iron, cobalt, and nickel

\begin{tabular}{|c|c|c|c|c|}
\hline $\begin{array}{l}\text { Composition } \\
\text { No. }\end{array}$ & Oxide added & $\begin{array}{c}\text { Amount of } \\
\text { oxide }\end{array}$ & $\mathrm{PbO}$ & $\mathrm{SiO}_{2}$ \\
\hline $\begin{array}{l}1 \\
2 \\
3 \\
4 \\
5\end{array}$ & $\begin{array}{l}\mathrm{Li}_{2} \mathrm{O} \\
\mathrm{Li}_{2} \mathrm{O} \\
\mathrm{Li}_{2} \mathrm{O} \\
\mathrm{Li}_{2} \mathrm{O} \\
\mathrm{Li}_{2} \mathrm{O}\end{array}$ & $\begin{array}{c}\text { Moles } \\
0.01 \\
.10 \\
.20 \\
.30 \\
.40\end{array}$ & $\begin{array}{c}\text { Moles } \\
0.99 \\
.90 \\
.80 \\
.70 \\
.60\end{array}$ & $\begin{array}{c}\text { Moles } \\
1.0 \\
1.0 \\
1.0 \\
1.0 \\
1.0\end{array}$ \\
\hline $\begin{array}{r}6 \\
7 \\
8 \\
9 \\
10\end{array}$ & $\begin{array}{l}\mathrm{Na}_{2} \mathrm{O} \\
\mathrm{Na}_{2} \mathrm{O} \\
\mathrm{Na}_{2} \mathrm{O} \\
\mathrm{Na}_{2} \mathrm{O} \\
\mathrm{Na}_{2} \mathrm{O}\end{array}$ & $\begin{array}{l}.01 \\
.10 \\
.20 \\
.30 \\
.40\end{array}$ & $\begin{array}{l}.99 \\
.90 \\
.80 \\
.70 \\
.60\end{array}$ & $\begin{array}{l}1.0 \\
1.0 \\
1.0 \\
1.0 \\
1.0\end{array}$ \\
\hline $\begin{array}{l}11 \\
12 \\
13 \\
14 \\
15\end{array}$ & $\begin{array}{l}\mathrm{K}_{2} \mathrm{O} \\
\mathrm{K}_{2} \mathrm{O} \\
\mathrm{K}_{2} \mathrm{O} \\
\mathrm{K}_{2} \mathrm{O} \\
\mathrm{K}_{2} \mathrm{O}\end{array}$ & $\begin{array}{l}.01 \\
.10 \\
.20 \\
.30 \\
.40\end{array}$ & $\begin{array}{l}.99 \\
.90 \\
.80 \\
.70 \\
.60\end{array}$ & $\begin{array}{l}1.0 \\
1.0 \\
1.0 \\
1.0 \\
1.0\end{array}$ \\
\hline $\begin{array}{l}16 \\
17 \\
18 \\
19 \\
20\end{array}$ & $\begin{array}{l}\mathrm{Rb}_{2} \mathrm{O} \\
\mathrm{Cs}_{2} \mathrm{O} \\
\mathrm{BeO} \\
\mathrm{MgO} \\
\mathrm{MgO}\end{array}$ & $\begin{array}{l}.40 \\
.40 \\
.40 \\
.01 \\
.10\end{array}$ & $\begin{array}{l}.60 \\
.60 \\
.60 \\
.99 \\
.90\end{array}$ & $\begin{array}{l}1.0 \\
1.0 \\
1.0 \\
1.0 \\
1.0\end{array}$ \\
\hline $\begin{array}{l}21 \\
22 \\
23 \\
24 \\
25\end{array}$ & $\begin{array}{l}\mathrm{MgO} \\
\mathrm{MgO} \\
\mathrm{MgO} \\
\mathrm{CaO} \\
\mathrm{CaO}\end{array}$ & $\begin{array}{l}.20 \\
.30 \\
.40 \\
.01 \\
.10\end{array}$ & $\begin{array}{l}.80 \\
.70 \\
.60 \\
.99 \\
.90\end{array}$ & $\begin{array}{l}1.0 \\
1.0 \\
1.0 \\
1.0 \\
1.0\end{array}$ \\
\hline $\begin{array}{l}26 \\
27 \\
28 \\
29 \\
30\end{array}$ & $\begin{array}{l}\mathrm{CaO} \\
\mathrm{CaO} \\
\mathrm{CaO} \\
\mathrm{SrO} \\
\mathrm{SrO}\end{array}$ & $\begin{array}{l}.20 \\
.30 \\
.40 \\
.01 \\
.10\end{array}$ & $\begin{array}{l}.80 \\
.70 \\
.60 \\
.99 \\
.90\end{array}$ & $\begin{array}{l}1.0 \\
1.0 \\
1.0 \\
1.0 \\
1.0\end{array}$ \\
\hline $\begin{array}{l}31 \\
32 \\
33 \\
34 \\
35\end{array}$ & $\begin{array}{l}\mathrm{SrO} \\
\mathrm{SrO} \\
\mathrm{SrO} \\
\mathrm{BaO} \\
\mathrm{BaO}\end{array}$ & $\begin{array}{l}.20 \\
.30 \\
.40 \\
.01 \\
.10\end{array}$ & $\begin{array}{l}.80 \\
.70 \\
.60 \\
.99 \\
.90\end{array}$ & $\begin{array}{l}1.0 \\
1.0 \\
1.0 \\
1.0 \\
1.0\end{array}$ \\
\hline $\begin{array}{l}36 \\
37 \\
38 \\
39 \\
40\end{array}$ & $\begin{array}{l}\mathrm{BaO} \\
\mathrm{BaO} \\
\mathrm{BaO} \\
\mathrm{ZnO} \\
\mathrm{CdO}\end{array}$ & $\begin{array}{l}.20 \\
.30 \\
.40 \\
.40 \\
.40\end{array}$ & $\begin{array}{l}.80 \\
.70 \\
.60 \\
.60 \\
.60\end{array}$ & $\begin{array}{l}1.0 \\
1.0 \\
1.0 \\
1.0 \\
1.0\end{array}$ \\
\hline $\begin{array}{l}41 \\
42 \\
43 \\
44 \\
45\end{array}$ & $\begin{array}{l}\mathrm{B}_{2} \mathrm{O}_{3} \\
\mathrm{Al}_{2} \mathrm{O}_{3} \\
\mathrm{La}_{2} \mathrm{O}_{3} \\
\mathrm{TiO}_{2} \\
\mathrm{GeO}_{2}\end{array}$ & $\begin{array}{l}.133 \\
.133 \\
.133 \\
.20 \\
.20\end{array}$ & $\begin{array}{l}.60 \\
.60 \\
.60 \\
.60 \\
.60\end{array}$ & $\begin{array}{l}1.0 \\
1.0 \\
1.0 \\
1.0 \\
1.0\end{array}$ \\
\hline $\begin{array}{l}46 \\
47 \\
48 \\
49 \\
50\end{array}$ & $\begin{array}{l}\mathrm{ZrO}_{2} \\
\mathrm{CeO}_{2} \\
\mathrm{ThO}_{2} \\
\mathrm{Cr}_{2} \mathrm{O}_{3} \\
\mathrm{FeO}\end{array}$ & $\begin{array}{l}.20 \\
.20 \\
.20 \\
.133 \\
.40\end{array}$ & $\begin{array}{l}.60 \\
.60 \\
.60 \\
.60 \\
.60\end{array}$ & $\begin{array}{l}1.0 \\
1.0 \\
1.0 \\
1.0 \\
1.0\end{array}$ \\
\hline $\begin{array}{l}51 \\
52 \\
53\end{array}$ & $\begin{array}{l}\mathrm{CoO} \\
\mathrm{NiO} \\
\mathrm{MnO}\end{array}$ & $\begin{array}{l}.40 \\
.40 \\
.40\end{array}$ & $\begin{array}{l}.60 \\
.60 \\
.60\end{array}$ & $\begin{array}{l}1.0 \\
1.0 \\
1.0\end{array}$ \\
\hline
\end{tabular}

Specimens were prepared for test by spraying a thin layer of "silver paint" 5 onto each face. A template was used during the spraying to leave an exposed circular area of silver $3 / 4 \mathrm{in}$. in diameter evenly centered on each face of the specimen. The paint was cured by air drying at room temperature for several hours. The resulting silver contacts were smooth and continuous before and after test. Results of a previous investigation [1] had shown that resistivity of alkali borosilicate and alkali-free borosilicate ceramic coatings appeared to be independent of thickness. It was therefore assumed that the contact resistance was small in comparison to the resistance of the specimen.

B A term applied to a preparation used for decorative purposes in the ceramic industry and more recently in making printed circuits; after curing, it consists of industry and more
nearly pure silver. 


\section{Chemical Analyses}

Several of the glasses were analyzed chemically. The compositions were chosen to represent high, intermediate, and low resistivity glasses. A comparison between the compositions calculated from the batch materials used and the compositions as determined analytically is given in table 2 .

TABLE 2. Chemical analysis of ternary lead silicates prepared by the equivalent substitution of beryllium, manganese, cobalt and zinc oxide for lead oxide in $\mathrm{PbO}: \mathrm{SiO}_{2}$

\begin{tabular}{|c|c|c|c|c|c|c|}
\hline \multirow{2}{*}{$\begin{array}{l}\text { Composi- } \\
\text { tion }\end{array}$} & \multicolumn{3}{|c|}{ Weight percent a } & \multicolumn{3}{|c|}{ Weight percent } \\
\hline & Oxide & $\begin{array}{l}\text { Calcu- } \\
\text { lated }\end{array}$ & Found & Oxide & $\begin{array}{l}\text { Calcu- } \\
\text { lated }\end{array}$ & Found \\
\hline $\begin{array}{l}18 \\
39 \\
53 \\
51\end{array}$ & $\begin{array}{l}\mathrm{BeO} \\
\mathrm{ZnO} \\
\mathrm{MnO} \\
\mathrm{CoO}\end{array}$ & $\begin{array}{r}4.9 \\
14.4 \\
12.8 \\
13.4\end{array}$ & $\begin{array}{r}4.3 \\
14.4 \\
12.1 \\
11.8\end{array}$ & $\begin{array}{l}\mathrm{PbO} \\
\mathrm{PbO} \\
\mathrm{PbO} \\
\mathrm{PbO}\end{array}$ & $\begin{array}{l}65.6 \\
59.1 \\
60.2 \\
59.8\end{array}$ & $\begin{array}{l}65.7 \\
59.3 \\
60.5 \\
59.5\end{array}$ \\
\hline
\end{tabular}

a Chemical analysis performed in the analytical laboratory of the Mineral Products Division under the supervision of L. Bean. The silica content was assumed to remain constant and was not determined.

\section{Test Equipment and Procedure}

A photograph of the equipment used for determining the resistivity of the specimens is shown in figure 1. The furnace, $A$, had a heating element consisting of Nichrome wire wound on a ceramic core. Within the core were located two circular stainless steel electrodes $3 / 4$ in. in diameter. An iron-constantan thermocouple was embedded in the top electrode, and the control thermocouple was embedded in the insulation. This second thermocouple activated the temperature control unit, B. The temperature of the top electrode was determined by the use of a potentiometer, F. A recording potentiometer, E, was used with a preamplifier, D, to graph the current passing through the specimen, in ranges $10^{-6}$ to $10^{-11}$ amp. An Ayrton shunt, C, was used in the input to the preamplifier to extend the range of the recorder to $10^{-3}$ amp. The resistance of the preamplifier input was 1,000 ohms.

The specimen to be tested was placed in the furnace so that the stainless steel electrodes were in contact with the silvered area on either side of the coated specimen (figs. 1 and 2). The furnace was heated at the rate of about $10 \mathrm{deg} \mathrm{C}$ per min and the current through the specimen was measured at 10 $\operatorname{deg} \mathrm{C}$ intervals. The voltage was applied during the entire heating period, polarity being reversed at least once each $20 \mathrm{deg} \mathrm{C}$. All determinations were made on at least triplicate specimens, one at a time. The current through the specimen was measured in amperes and the resistivity (ohm-cm) calculated from the current, voltage, and dimensions of the specimen. When the voltage drop across the shunt exceeded 1 percent of the input voltage or $2 \mathrm{v}$, this voltage drop was taken into consideration in calculating the resistivity. Edge effects were not included in calculating the effective area of the specimen because of the general inaccuracy in this type of measurement. The silvered area was as-

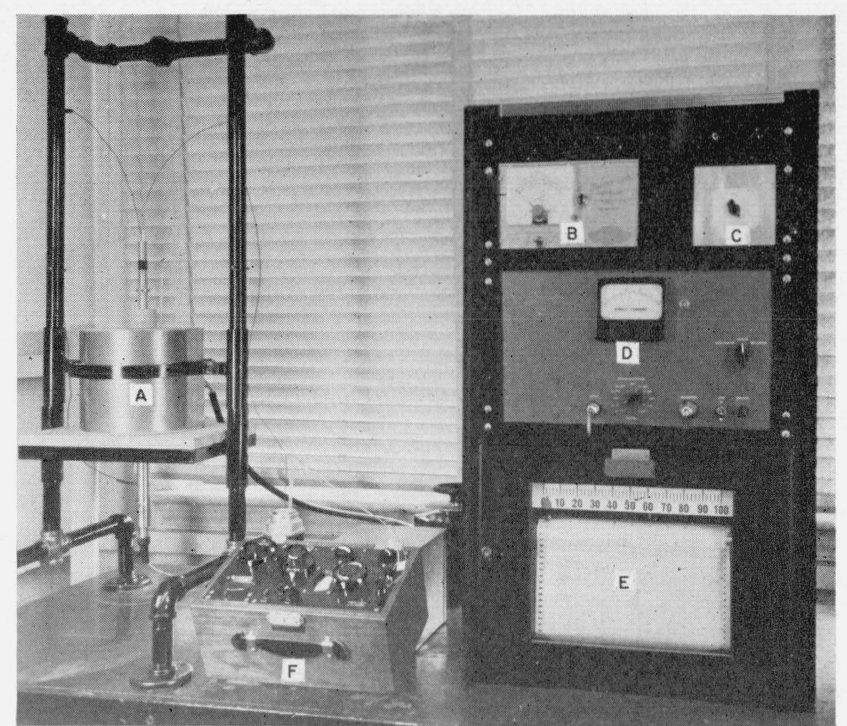

FIgURE 1. Testing arrangement for the measurement of electrical resistivity of ceramic coating materials at elevated temperatures.

A, Furnace; B, temperature control unit; C, Ayrton shunt; D, d-c amplifier; $\mathrm{E}$, recording potentiometer; $\mathrm{F}$, potentiometer.

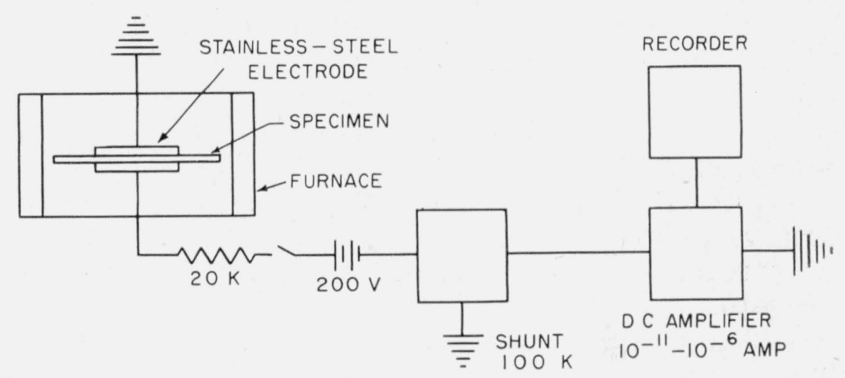

Figure 2. Testing arrangement for the measurement of electrical resistivity of ceramic coating materials at elevated temperatures.

sumed to be the effective area. In this type of measurement where the resistivity values are high, a 100-percent difference between duplicate determinations may be obtained. The precision was found to be, in general, of this order of magnitude or better. Above about $200^{\circ} \mathrm{C}$ the same values for the current were obtained with and without use of a guard ring. The surface conduction was therefore assumed to be negligible above $200^{\circ}$ compared to that of the volume.

The effect of polarization was directly observable in the values of current before and after reversal of the direction of flow through the specimen. In a specimen containing 0.4 mole of sodium, where polarization effects must be expected to be high, a maximum difference of about 6 percent was observed on reversal at the highest temperatures above about $300^{\circ} \mathrm{C}$. This level of error introduces no observable error into the activation energies calculated from these data, and has therefore been ignored. 


\section{Results and Discussion}

\subsection{Silica Glass and Quartz}

A comparison between the resistivity of silica glass and quartz is given in figure 3. These experiments were performed, (a) to measure the resistivity of silica glass because it is one end member of the $\mathrm{PbO}: \mathrm{SiO}_{2}$ system, and (b) to compare the resistivity of two allotropic forms of silica in order to obtain information regarding the conduction mechanism.

The observed conduction through both quartz and silica glass might well be due, in part at least, to the presence of traces of impurities since a trace of impurity would yield many potential conduction ions. For example, an impurity of one part sodium per billion of silica would be equivalent to about $10^{13}$ sodium ions per gram of silica. The results of spectrochemical analyses (table 3 ) indicate that each gram of silica glass or quartz actually contained $10^{15}$ to $10^{19}$ ions of various impurities. While these ions would seek the lowest available potential energy holes in the silicate structure, it is quite conceivable that at least some of them might still contribute towards electrical conduction, especially at higher temperatures. Warburg and Tegetmeier [13] reported that when a quartz specimen was electrolyzed, sodium amalgam being used as the anode, sodium migrated through the specimen in amounts in accordance with Faraday's law, while the weight of the specimen remained unchanged. These investigators concluded from this result and from additional experiments that the conduction was due to the presence of sodium silicate in the quartz; their analysis showed 1 part in 2,300 , hence the quartz was regarded as a very dilute solution of sodium silicate.

As shown in figure 3 , the resistivity of quartz measured perpendicular to the optic axis is greater than that of the same material measured parallel to the optic axis, over the range $200^{\circ}$ to $500^{\circ} \mathrm{C}$. Quartz has two crystalline modifications, $\alpha$ and $\beta$. For alpha quartz, the existence of tunnels parallel to the optic axis has been suggested in the literature, while similar tunnels are postulated to be absent in the directions perpendicular to the optic axis [14]. This tunnellike structure is supposedly responsible for the

TABLE 3. Qualitative spectrochemical analysis of silica glass and quartz

\begin{tabular}{|c|c|c|c|c|}
\hline \multirow[b]{2}{*}{ Impurity } & \multicolumn{2}{|c|}{ Quartz } & \multicolumn{2}{|c|}{ Silica glass } \\
\hline & $\begin{array}{l}\text { Percentage by } \\
\text { weight a }\end{array}$ & $\begin{array}{l}\text { Ions per gram } \\
\text { of silica }\end{array}$ & $\begin{array}{l}\text { Percentage by } \\
\text { weight a }\end{array}$ & $\begin{array}{l}\text { Ions per } \\
\text { gram of } \\
\text { silica }\end{array}$ \\
\hline $\mathrm{Ag} \ldots .$. & $0.0001 \ldots$ & $10^{15} \ldots \ldots$ & $0.0001 \ldots$ & $10^{15}$ \\
\hline Al..... & 0.01 to $0.1 \ldots$ & $10^{18}$ to $10^{19}$ & 0.001 to 0.01 & $10^{17}$ to $10^{18}$ \\
\hline $\mathrm{Ca}$ & 0.0001 to 0.001 & $10^{16}$ to $10^{17}$ & 0.0001 to $0.001 \ldots$ & $10^{16}$ to $10^{17}$ \\
\hline $\mathrm{Cu}$ & 0.0001 & $10^{16}$ & 0.0001 & $10^{16}$ \\
\hline $\mathrm{Fe} \ldots$ & 0.001 to 0.01 & $10^{17}$ to $10^{18}$ & 0.0001 to 0.01 & $10^{17}$ to $10^{18}$ \\
\hline $\mathrm{Mg}_{\ldots} \ldots$ & 0.001 to $0.01 \ldots$ & $10^{17}$ to $10^{18}$ & 0.001 to 0.001 & $10^{16}$ to $10^{17}$ \\
\hline $\mathrm{Na}$ & 0.001 to $0.01 ?$ & $10^{17}$ to $10^{18} ? \ldots$ & 0.001 to 0.01 & $10^{17}$ to $10^{18}$ \\
\hline
\end{tabular}

a Analysis performed in the Spectrochemistry Section of the Chemistry Division under the supervision of B. F. Scribner.

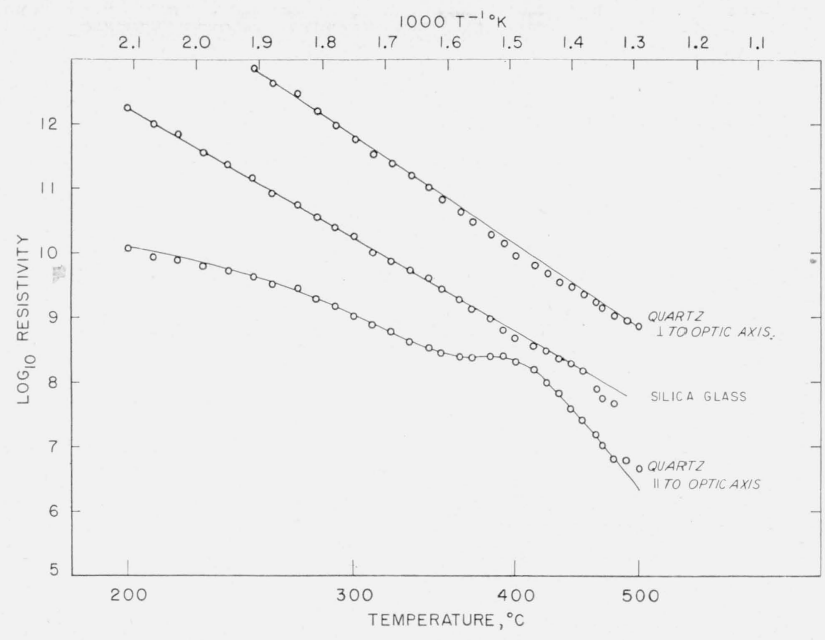

FiguRE 3. Resistivity-temperature curves for silica glass and for quartz with optic axis parallel and perpendicular to applied field.

ease of ion migration in quartz plates with optic axis parallel to the applied field [15]. This hypothesis is in agreement with the results plotted in figure 3 .

From figure 3 it is also seen that the resistivity curve for quartz measured parallel to the optic axis does not follow the Rasch-Hinrichsen law, log $\mathrm{R}=(\mathrm{A} / \mathrm{T})+\mathrm{B}$, over the entire temperature range that was studied. This effect was observed on four independent determinations using four different specimens. The change in slope of the temperatureresistivity curve indicates that there is a change in the mechanism of conduction in the quartz whose optic axis is parallel to the applied field when the temperature exceeds about $360^{\circ} \mathrm{C}$.

The transition temperature of $\alpha$ to $\beta$ quartz is given as $573^{\circ} \mathrm{C}$. However, $\mathrm{X}$-ray diffraction studies performed on quartz [16] indicate that a partial reversible transition from the $\alpha$ to the $\beta$ form may occur between room temperature and $573^{\circ} \mathrm{C}$. If this apparent behavior of quartz is further substantiated by additional X-ray studies, the results may be helpful in explaining the observed change in slope in the temperature-resistivity curve.

It is not within the scope of this paper to discuss the conduction mechanism in silica in any greater detail. The results do, however, indicate that a more critical study of the electrical properties of allotropic modifications of silica might yield important information regarding the mechanism by which ions migrate through a structure composed of $\mathrm{SiO}_{4}$ groupings. In addition such a study might throw further light on the exact structural arrangements of the various modifications of silica.

\subsection{Alkali-Lead Silicates}

Figure 4 shows the resistivity-composition isotherms at $200^{\circ}, 300^{\circ}$, and $400^{\circ} \mathrm{C}$ that were obtained when lead oxide was replaced with equivalent amounts of lithium oxide, sodium oxide, or potassium oxide. Crossover of curves which are similar to the ones shown in this figure are reported in the 


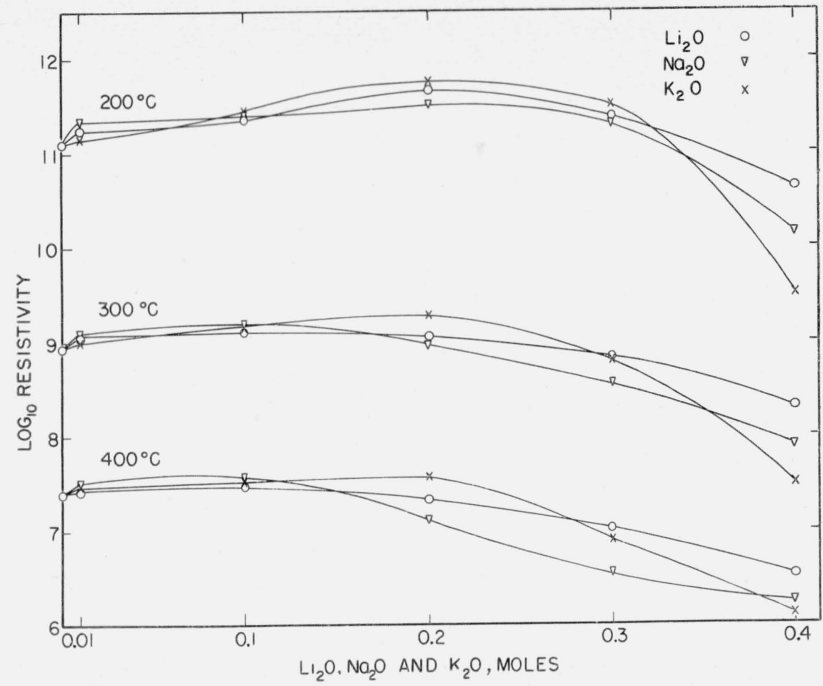

FIGURE 4. Resistivity-composition isotherms for lithium, sodium, and potassium lead silicates prepared by equivalent substitution of $\mathrm{Li}_{2} \mathrm{O}, \mathrm{Na}_{2} \mathrm{O}$, or $\mathrm{K}_{2} \mathrm{O}$ for $\mathrm{PbO}$ in $\mathrm{PbO}: \mathrm{SiO}_{2}$.

literature for resistivity-composition isotherms as well as for viscosity-composition curves for alkali silicates [17]. It will be noted in figure 4 , that replacement up to about 0.3 mole at $200^{\circ} \mathrm{C}, 0.2$ mole at $300^{\circ} \mathrm{C}$, and 0.1 mole at $400^{\circ} \mathrm{C}$ yield glasses whose resistivities are somewhat greater than the resistivity of the base composition. Such behavior suggests that additions of alkali at the expense of lead up to a certain optimum amount actually tightens the structure, thereby making migration of ions more difficult. A tightening of this type may be expected if the lead is acting as a network former, a role that it is reported to assume at high concentrations [18]. As more alkali ions are substituted for lead, however, a point should be reached where the presence of extra alkali ions would more than compensate for the tightening effect resulting from the removal of lead from the network positions. The resistivity should then decrease upon further addition of alkali ions and figure 4 shows that such a decrease does occur.

\subsection{Alkaline Earth and Transitional Element Lead Silicates}

Figure 5 shows the resistivity-composition isotherms for alkaline earth lead silicates, while the resistivity-temperature curves for iron, cobalt, and nickel lead silicates are given in figure 6 .

In figure 5, there is a definite trend toward increased resistivity with increasing concentration of the alkaline earth oxide. A behavior of this type might indicate a general tightening of the structure from the replacement of lead with the alkaline earth ion, making it more difficult for alkali ions, present as trace impurities, to migrate through the structure. A second interpretation might be based on the possibility that lead and the alkaline earth ions are themselves responsible for at least part of the conduction. However, such an interpretation would be

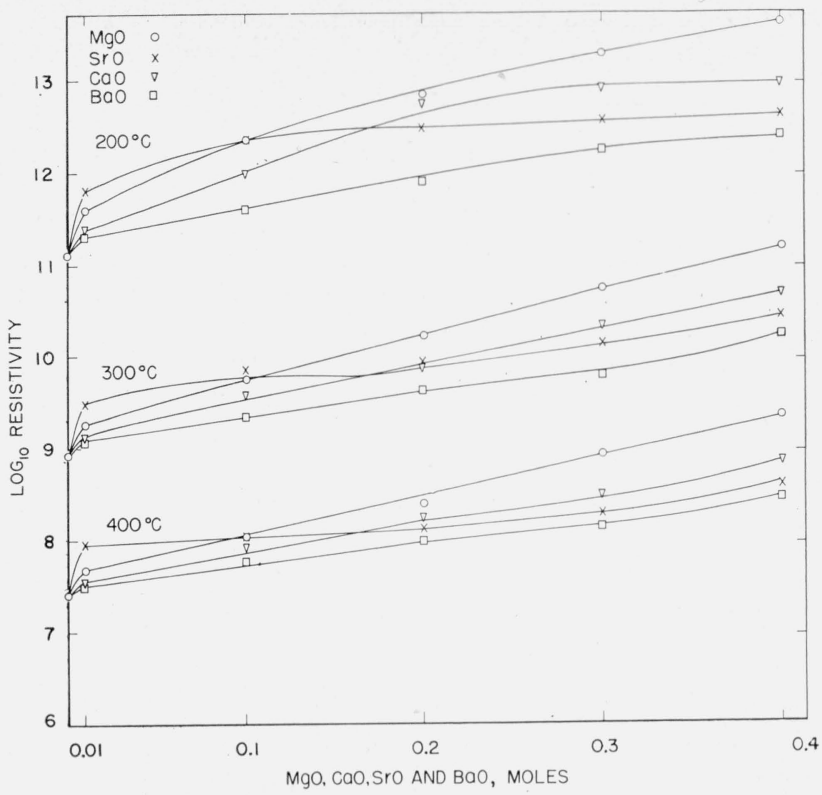

FIGURE 5. Resistivity-composition isotherms for magnesium, calcium, strontium, and barium lead silicates prepared by equivalent substitution of $\mathrm{MgO}, \mathrm{CaO}, \mathrm{SrO}$, or $\mathrm{BaO}$ for $\mathrm{PbO}$ in $\mathrm{PbO}: \mathrm{SiO}_{2}$

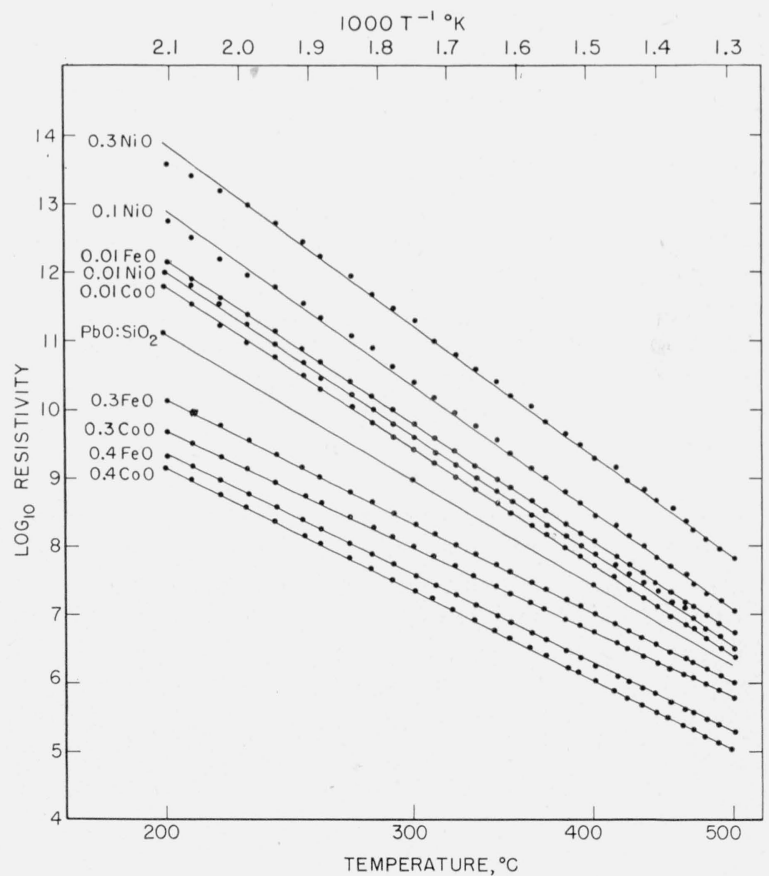

FIgURE 6. Resistivity-temperature curves for $x \mathrm{FeO}:(1-x)$ $\mathrm{PbO}: \mathrm{SiO}_{2}, x \mathrm{CoO}:(1-x) \mathrm{PbO}: \mathrm{SiO}_{2}$ where $x$ ranges from 0 to 0.4 and for $y \mathrm{NiO}:(1-y) \mathrm{PbO}: \mathrm{SiO}_{2}$ where $y$ ranges from 0 to 0.3 .

meaningless until it can be demonstrated by some suitable experimental technique that ions other than alkalies are free to move in a rigid silicate network.

The slopes on the curves in figure 6 show that while iron and cobalt tend to decrease the heat of activation when 0.3 and 0.4 mole of these oxides 
are added to the base composition, nickel tends to increase the heat of activation at all concentrations studied. The addition of small amounts of iron and cobalt appears to have the same effect upon heat of activation as a small amount of nickel. One possible reason for this behavior may be that at small concentrations these ions (also the nickel ion), which are about as small as a lithium ion, enter deep potential energy holes and cause a tightening of the structure. The nickel glasses were also much more difficult to prepare than the iron or cobalt glasses, in that they showed a greater tendency to devitrify.

\section{Interpretation of Resistivity Data in Terms of Energy Considerations}

In view of the finite conductivity found in the quartz used as the raw material, it seems probable that the major part of the conduction in all the glasses studied may have been due to alkali ions, either added or present as impurities. ${ }^{6}$ This assumption will be implicit in the following discussions which will apply to ternary lead silicates in which 0.4 mole $\mathrm{PbO}$ in a base composition $\mathrm{PbO}: \mathrm{SiO}_{2}$ was replaced by oxides the ions of which are given in figure 7 .

\subsection{Electrostatic Bonding Energy Considerations}

Various investigations [19] have used charge and ionic radius to obtain a semiquantitative classification of glass constituents. Such expressions as $e / r, e / r^{2}, Z e / r$, or $Z e / r^{2}(Z, e$, and $r$ representing valence, charge of the electron, and ionic radius) have been used to express the relative magnitude of cation-oxygen bond energy in vitreous silicates. When other ions were introduced into the base composition one of the results may have been a tightening or loosening of the silicate framework. The extent of this tightening (or loosening) of the structure was probably dependent, in part at least, upon the size, charge, and the position occupied by the cation added to the base composition. The electrostatic bonding energy was therefore used as a first approximation to estimate the relative tightening (or loosening) effect produced by introducing other ions into the base composition. The equation for electrostatic bonding energy [20] is $E=-Z_{1} Z_{2} e^{2} / R_{12}$; where $E=$ electrostatic bonding energy, $Z_{1}$ and $Z_{2}$ are the valences of the cation and the oxygen ion respectively, $e$ is the charge of the electron, and $R_{12}$ is the cation to oxygen distance. This equation states that the magnitude of the bonding energies increases with the valences and decreases with the atomic separation. Figure $7^{7}$ is a plot of the logarithm of the resistivity at $200^{\circ} \mathrm{C}$ against the logarithm of the quantity $\left(-e^{-2} E\right)$ which is proportional to the electrostatic bonding energy. ${ }^{8}$ Possible oxidation states

\footnotetext{
${ }^{6}$ Since all glasses contain some water it is of course possible that hydrogen ions may also contribute towards conduction

Similar curves were obtained at 300,400 , and $500^{\circ} \mathrm{C}$

8 Crystal radii were used in the calculation of electrostatic bonding energies. It is realized that these ionic radii values are relative. In a glass, which is sometimes described as a supercooled liquid, absolute values for ionic radii may be expected to be different from crystal radil values. Changes in coordination
} number may also affect the sizes of ionic radil.

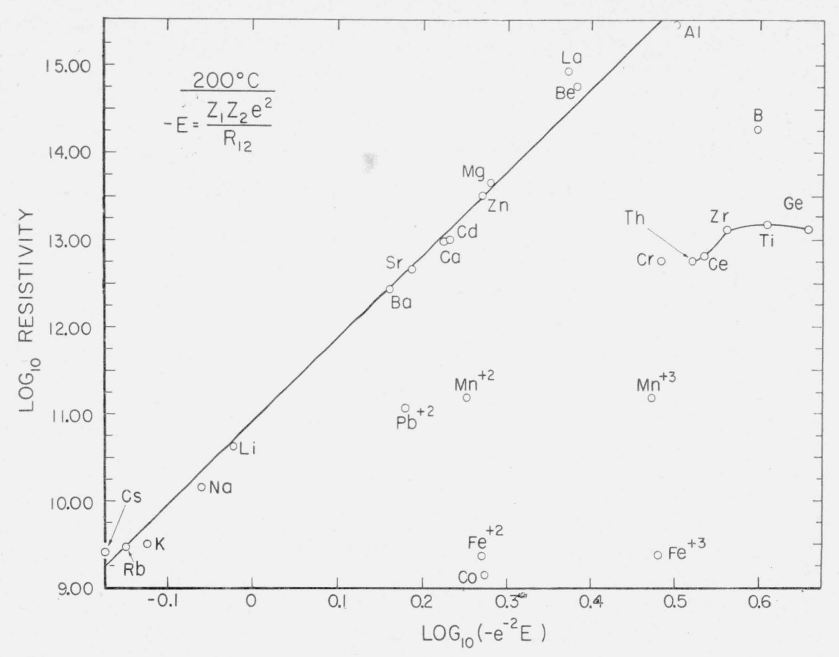

Figure 7. Resistivity-bonding energy isotherm for lead silicate and for ternary lead silicates orepared by the equivalent replacement of $0.4 \mathrm{PbO}$ in the base composition $\mathrm{PbO}: \mathrm{SiO}_{2}$ by each of the ions listed on the curves.

In the bonding energy expression, $\mathrm{E}=$ electrostatic bonding energy, $\mathrm{e}=$ charge of the electron, $Z_{1}$ and $Z_{2}$ are the valences of the cation and oxygen ion, respectively, and $\mathrm{R}_{12}=$ cation-oxygen distance.

are indicated for iron and manganese to illustrate the variable valency of transitional element ions.

It is interesting to note that the ions added to the base composition, seem to fall into three general classes. The first class contains ions of groups I, II, and the ions $\mathrm{Al}$ and La, the second group contains tetravalent ions, and the third, less defined group, contains the ions chromium, manganese, iron, and cobalt. With the exception of iron and cobalt only the alkali ions added to the base composition decreased the resistivity. This observation appears to be consistent with the assumption that the major part of the conduction may be due to the alkali ions.

Figure 8 gives a plot of upper and lower limits of heats of activation against composition for lead silicate and for lithium, sodium, and potassium lead silicates. The heats of activation were calculated from the slopes of curves obtained by plotting the logarithm of the experimentally determined resistivity values against the reciprocal of the absolute temperature. The data indicate that there is an initial rise in heat of activation followed by a drop at the 0.4 mole composition. An initial rise in heat of activation is in accord with the suggestion made earlier that initial replacement of lead by alkali might yield a tightening of the structure.

A plot of heat of activation, $\Delta \mathrm{H}^{*}$, against the logarithm of the frequency factor, $\log A$, is given in figure 9 . The quantities $\log \mathrm{A}$ and $\Delta \mathrm{H}^{*}$ appear as parameters in the equation $\log \rho=\log \mathrm{A}+$ $\left(\Delta \mathrm{H}^{*} / 2.3 \mathrm{RT}\right)$ where $\rho$ is the resistivity. Although the scatter is relatively large and $\log \mathrm{A}$ is a complex quantity, the decrease in $\log \mathrm{A}$ observed with the alkali ions contrasted to the constancy or slight increase in $\log \mathrm{A}$ for the other ions is consistent with the alkali ions alone providing additional charge carriers. 


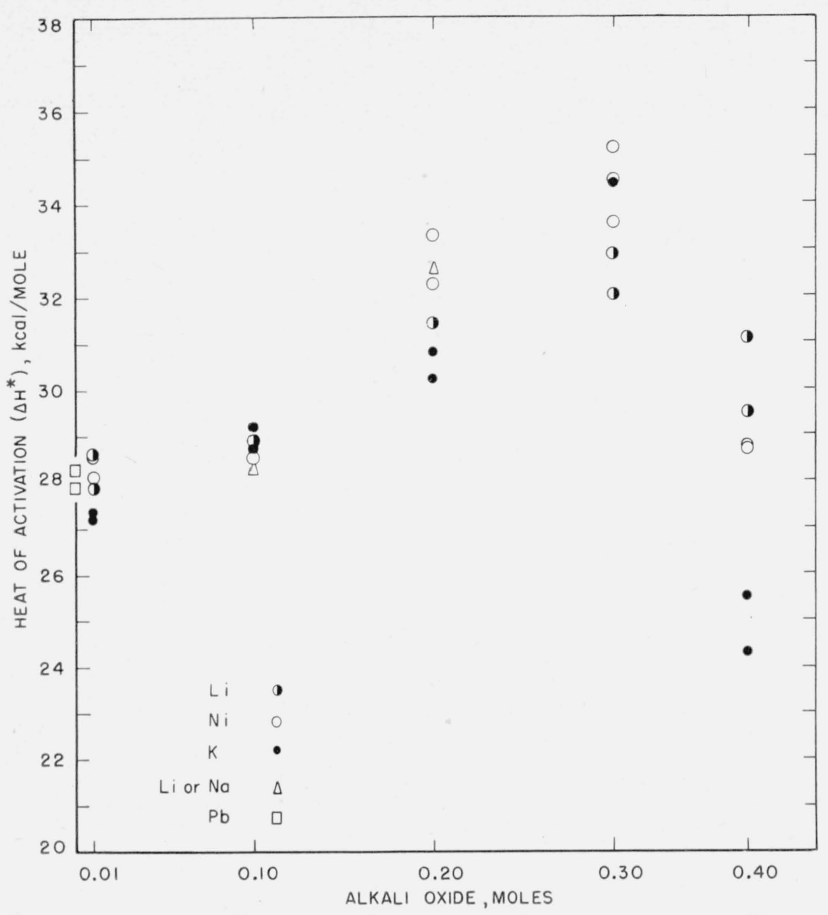

FiguRe 8. Upper and lower limits of heat of activationcomposition data for lead silicate and for lithium, sodium, and potassium lead silicates prepared by equivalent substitution of $\mathrm{Li}_{2} \mathrm{O}, \mathrm{Na}_{2} \mathrm{O}$, or $\mathrm{K}_{2} \mathrm{O}$ for $\mathrm{PbO}$ in $\mathrm{PbO}: \mathrm{SiO}_{2}$.

Figure 10 shows heat of activation-ionic radius curves. For the alkali ions, $\Delta \mathrm{H}^{*}$ decreases from lithium to potassium and then begins to increase from potassium to rubidium. The minimum or at least change in slope at potassium appears to be real and beyond experimental error. It can be explained in the following way.

Before an alkali ion can migrate, the free energy of activation must be exceeded. This involves overcoming the chemical binding energy (breaking the cation-oxygen bond) and, in addition, sufficient energy (network repulsion energy term) must be supplied to the alkali ion so that it can pass through the interstitial hole. From the standpoint of the chemical binding energy term, the smaller the cation the more energy it will take to break the cationoxygen bond. On the other hand, the smaller the cation the smaller will be the network repulsion energy term required to move it into the next interstitial hole. Assuming that the approximate structure of glass does not differ appreciably from a model such as is depicted by Poncelet [21], the average diameter of the opening between interstices is approximately equal to that of an oxygen ion. Anderson and Stuart [22] in discussing the structure of glass state "Although it is true that the volume of the interstice may change when an ion is added, there are four doorways connecting the interstice containing the ion to adjacent interstices and the average size of the doorway through which the ion must pass will not change significantly." 9 An ion smaller than

- It is of course possible that some of the openings between interstitial holes may be larger than the circumference of an oxygen ion. Even if this would be the case the discussion would still be generally the same as the one presented.

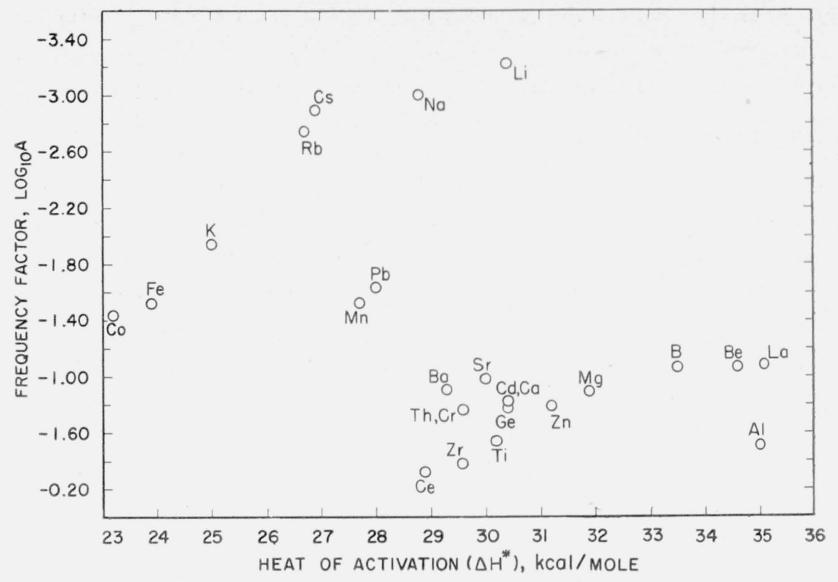

FiguRE 9. Heat of activation-frequency factor data for lead silicate and for ternary lead silicates prepared by the equivalent replacement of $0.4 \mathrm{PbO}$ in the base composition $\mathrm{PbO}: \mathrm{SiO}_{2}$ by each of the ions listed.

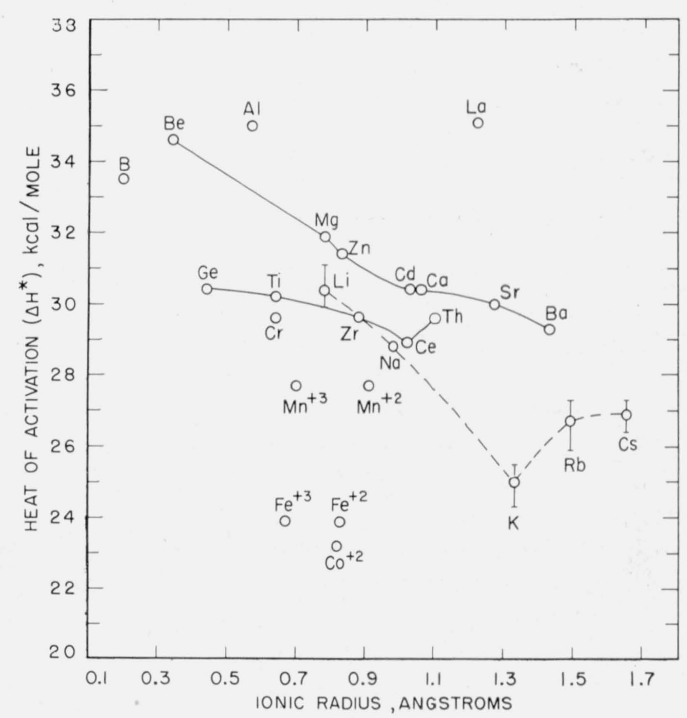

FIGURE 10. Heat of activation-ionic radius curves for ternary lead silicates prepared by the equivalent replacement of 0.4 $\mathrm{PbO}$ in the base composition $\mathrm{PbO}: \mathrm{SiO}_{2}$ by each of the ions listed on the curves.

oxygen should pass through the opening to the interstitial hole with considerable ease whereas ions larger than oxygen have to expand the entrance to the interstitial hole before they can pass through. Hence, in the latter case the network repulsion energy term may become a large fraction of the total energy requirement and the ion would have to surmount a higher energy barrier before it could migrate into the next interstice. The ions rubidium and cesium are larger than oxygen therefore the network repulsion energy term for each of these cations may be appreciably larger than that for any of the first three alkali ions. This increase in the network repulsion energy term apparently more than compensates for the decrease in the chemical binding energy term with a net result that the total energy of activation is 
greater for rubidium or cesium than for potassium. This explanation should be accepted with some reservation until additional experimental data are available.

The preceding discussions may be summarized as follows: The data indicate that the ions added to the base composition fall into four groups: (a) alkali ions tend to decrease $\log \mathrm{A}$ and to vary the heat of activation, with an indication of decreasing the heat of activation with increasing radius, and with a possible minimum or a change in slope at potassium; (b) iron and cobalt do not appear to affect $\log \mathrm{A}$ but decrease the heat of activation; (c) manganese affects neither log A nor the heat of activation; and (d) the other ions increase $\log \mathrm{A}$, and increase the heat of activation, with an indication that within a group of isovalent ions the heat of activation decreases with increasing radius (see fig. 10). A more complete interpretation of the data cannot be given until such time as experimental evidence is obtained to determine conclusively whether or not nonalkali ions (also hydrogen ions from water in the glass) take part in the conduction process and if so, under what conditions and to what extent. In this connection diffusion and transference number data should yield valuable information.

\section{Summary}

Resistivity data were presented for silica glass, for quartz, and for ternary lead silicates prepared by the partial substitution of 25 oxides, one at a time, for lead oxide in a base composition of $\mathrm{PbO}: \mathrm{SiO}_{2}$.

The results of this investigation were discussed on the basis that alkali ions may have been the only conducting ions. For the nonalkali glasses studied, the nonalkali ions introduced into the base composition were assumed to affect the migration of alkali ions, present as impurities, by altering the silicate structure.

The resistivity of silica glass was found to be less than that for quartz measured perpendicular to the optic axis but greater than that for quartz measured parallel to the optic axis.

For quartz measured parallel to the optic axis the data indicate that a change in the conduction process occurs at about $360^{\circ} \mathrm{C}$.

Results on the ternary lead silicates investigated indicate that the relative change in resistivity produced by substituting different ions for lead in the base composition is dependent on the nature of the ions added.
Relative to the base composition, substitution for 0.4 mole $\mathrm{Pb}^{+2}$ of alkali ions, iron, and cobalt decreased the resistivity, manganese did not affect the resistivity, and the other ions increased it.

The authors thank J. D. Hoffman of the Polymer Structure Section and A. Franklin of the Porcelain and Pottery Section of the Bureau for their helpful discussions on certain aspects of the problem.

\section{References}

[1] S. W. Strauss, L. E. Richards, and D. G. Moore, Effect of temperature on the electrical resistivity of several ceramic and silicone-type coatings, ASTM Special Tech. Publ. No. 153, p. 101 (1953).

[2] H. Buff, Liebig Ann. 90, 257 (1854).

[3] W. Beetz, Liebig Ann. 92, 452 (1854).

[4] E. Seddon, E. J. Tippet, and W. E. S. Turner, J. Soc. Glass Tech. 16, 451 (1932).

[5] G. W. Morey, The properties of glass, ch. XVII, XVIII (Reinhold Publishing Corp., New York, N. Y., 1954).

[6] E. J. Murphy and S. O. Morgan, Bell System Tech. J. 16, $493(1937) ; \mathbf{1 7}, 640(1938) ; \mathbf{1 8}, 502(1939)$.

[7] J. M. Stevels, Progress in the theory of the physical properties of glass, ch. III, IV (Elsevier Publishing Co. Inc., 1946).

[8] J. E. Stanworth, Physical properties of glass, pt. II, ch. 6 (Oxford Univeristy Press, 1950).

[9] W. Eitel, The physcial chemistry of the silicates, pt. A, section II (Univeristy of Chicago Press, 1954).

[10] R. Smoluchowski, J. E. Meyer, and W. A. Weyl, Phase transformation in solids, p. 307 (John Wiley \& Sons, Inc., New York, N. Y., 1951).

[11] H. Moore and R. C. DeSilva, J. Soc. Glass Tech. 36, 168, $5(\mathrm{~T})(1952)$.

[12] G. Gehlhoff and M. Thomas, Z. Tech. Phys. 6, 544 (1925).

[13] Mellor's Comprehensive Treatise on Inorganic and Theoretical Chemistry, 6, 265 (Longmans, Green \& Co., 1947).

[14] R. E. Gibbs, Proc. Roy. Soc., London [A] 110, 443 (1926).

[15] P. M. Harris and C. E. Waring, J. Phys. Chem. 41, 1077 (1939).

[16] Private communication from A. Van Valkenberg of NBS Constitution and Microstructure Section.

[17] W. Eitel, The physical chemistry of the silicates, p. 214, 236 (University of Chicago Press, 1954).

[18] J. M. Stevels, Progress in the theory of the physical properties of glass, p. 18 (Elsevier Publishing Co., Inc., 1946).

[19] N. J. Kreidl, Ceramic Age 5\%, 256 (1948).

[20] B. E. Warren and A. G. Pincus, J. Am. Ceram. Soc. [10] 23, 301 (1940).

[21] E. F. Poncelet, Verres et Refractaires 2,208 (1948).

[22] O. L. Anderson and D. A. Stuart, J. Am. Ceram. Soc. [12] 3\%, 579 (1954).

Washington, November 3, 1955. 